\title{
ESSE BOM AMIGO, O LIVRO \\ Representações da leitura. Paraná (1880-1930)
}

Cláudio DeNipoti ${ }^{1}$

Resumo: Este artigo busca apresentar alguns dos resultados da pesquisa sobre a leitura no passado, feita a partir de fontes no Paraná da virada do século. O artigo busca compreender como a própria leitura era compreendida e representada no passado, a partir de casos locais.

Palavras-chave: História da leitura - História do Brasil República - leitura

O estudo que realizei sobre o livro e a leitura no Paraná, entre 1880 e 1930, revelou um rico universo cultural, calcado na palavra impressa. No período estudado, verificou-se uma farta produção editorial, representada em várias dezenas de periódicos literários, humorísticos, de associações, etc., e em um crescimento crescente da edição de livros locais, além de um comércio abundante, embora concentrado na capital paranaense. $^{2}$

No decorrer da pesquisa, contidas naqueles mesmos periódicos referidos acima, descrições sobre o livro e a leitura manifestavam a importância que aquela sociedade, ou que a parcela letrada daquela sociedade, dava a esses temas.

Essas construções, calcadas no trinômio tradição/ educação/meios de comunicação, apontados por Moscovici como fontes básicas do conhecimento, embora busquem uma identidade com um certo conhecimento científico (aquele comprometido com a idéia de progresso), podem ser mais identificados com a idéia - também teorizada por Moscovici - de representação social, ou um conhecimento não sistematizado

\footnotetext{
${ }^{1}$ Departamento de História - Universidade Estadual de Londrina

${ }^{2}$ Esta discussão está delineada no primeiro capítulo da tese de doutoramento da qual esta comunicação foi retirada. Ver: DENIPOTI, 1998.
} 
do real, forjado na sociedade com o objetivo de ordenar o meio (MOSCOVICl, 1990).

Essas representações, reconhecidas nesse meio por sua carga de verossimilhança e pelos elementos culturais comuns aos membros daquela sociedade (as "teorias implícitas" de Moscovici) podem ser levantadas na busca da compreensão do papel que a leitura exerceu no passado em questão.

Nesse sentido, livro, leitura e bibliotecas constituem-se em uma fonte central de preocupação para as pessoas envolvidas na escrita e na leitura de livros, jornais e revistas no Paraná da virada do século.

No que se refere às associações estabelecidas com o objeto físico constituído pelo códice ocidental, podemos partir de uma primeira fonte, bastante rica, e um tanto longa, que peço a licença do leitor para transcrever:

Confesso ingenuamente - sempre que me entra em casa um livro novo, experimento duas impressões que mutuamente se contradizem.

Alegro-me de o ver apparecer; entristeço-me, sabendo de antemão que esse livro, sobretudo quando vibre da sonoridade de um nome victorioso, virá tantalizar-me.

Repetidas vezes fujo-lhes, colloco-os a respeitável distância da minha ardente expectativa, sequestro-os ao meu olhar curioso para o antro de uma gaveta, hermeticamente fechada como um calaboiço!

Não dispondo do tempo indispensável para aprecial-os, diligenceio por todas as maneiras de esquecel-os.

Mas os scelerados attrahem-me, cantam em surdina no fundo das gavetas promessas sugestivas, provocações fascinadoras...

E é raro que eu triumphe da seduccção em que elles me envolvem; em questão de dias! Por fim, resgato os 
[ilegível] e acabo sacrificando-Ihes em holocausto algumas horas cerceadas ao meu trabalho sem tréguas e cincoenta por cento, pelo menos, do meu sono.

\section{$[\cdots]$}

Era forçoso attendel-os; exigia-o a cortezia que devemos as visitas amáveis e solicitava-o a voz imperiosa que nos impelle, para as curiosidades irresistíveis. E afinal, elles merecem todas as dedicações, desde o artigo de jornal que se não escreve até a noite branca em que se não dorme.

Indiquem-me, se o conhecem, o nome do amigo ideal que possua, como o livro, o segredo de nos confortar, sem nada exigir, a lucida dupla vista de nos entender, sem nos interrogar, o maravilhoso poder de nos abrir para o infinito a janella da visão, a suavidade ineffável que acaricia a alma e o sorriso leve e alado, como uma borboleta de primavera, que aligeira o espírito (TORREZÃO, 1889, p. 82).

Depreende-se, deste texto de Guiomar Torrezão, uma série de relações existentes entre o leitor (no caso, a leitora) e o livro, muitas das quais antecedendo a própria leitura. A mais presente é a atribuição de qualidades humanas aos objetos, que, em suas ações imaginárias, tornam-se "scelerados" ou "amigos", com vontade própria, mais forte que a determinação do leitor. É comum encontrarmos referências, no material estudado, à amizade ou ao companheirismo que o livro pode proporcionar ao leitor. Dario Vellozo, por exemplo, citava Bernardin de Saint-Pierre ao afirmar que "um bom livro é um bom amigo" (VELLOZO, 1916, p. 112145). Da mesma forma, para os escritores da revista Cenáculo, o livro infantil era "um bello companheiro" (Anon., 1897, p. 187190). Entendido como tal, o livro podia despertar um grande número de diferentes emoções entre seus leitores, normalmente aquelas surgidas em relações de amizade. O livro de Saint-Pierre 
enobrecia e confortava Dario Vellozo através de "thezouros moraes e nobres ensinamentos" (VELLOZO, 1916, p. 112-145), da mesma forma que As Peregrinas, de Lycio de Carvalho, fizeram Leoncio Correia "sentir n'alma essa doce e commovedora sympathia que inspiram os corações alanhados pelas desventuras [...]" e o Luar de Inverno, de Silveira Neto, era "um livro vibrante, no qual se alteiam estrophes que nos commovem até as lagrimas" (CORREIA, 1895, p.85; 253). Deusdedit Moura Brasil, ao final do um atribulado processo de aprendizado (ver: DENIPOTI, 1998B), encontrava no livro "a jóia ou o brinco que deleitará e confortará o Espírito em seguida"(MOURA BRASIL, 1920. p. 7). O resenhista do Cenáculo, também destilava emoções "sadias" que faziam-no sentir "vibratizado", a partir da leitura do relato da viagem de Andrade Muricy Á Foz do lguassú (Anon., 1986, p. 157-160).

Esta prática de leitura, que identifica diferentes emoções com o livro, pode ser associada àquilo que Peter Gay chama de prática econômica da leitura. Se o ato de ler "prova o id ao simular a satisfação dos instintos, lisonjeia o ego com belezas formais, aplaca o superego ao incluir o leitor numa comunidade moral invisível em que é feita justiça aos maus e aos inocentes", ele prova ser uma atividade econômica ao evitar que o leitor se exponha aos perigos envolvidos em buscar aquelas emoções por conta própria, sem a intermediação do escritor (GAY, 1990, p. 145). Por outro lado, a apreciação dos livros como "amigos" pode ter uma raiz no século XVIII, à medida que possamos inferir maior ou menor grau de indentificação da leitura do período com a leitura do iluminismo, que se pensava libertadora e dotada de valores universais. Seja qual for a origem de tais associações, elas demonstram intimidade com o objeto físico que contém aquilo que se deseja ler, ao mesmo tempo que aponta para uma visão favorável da leitura e do livro - qualquer leitura e qualquer livro até que eles mesmos - livro e leitura - provém não serem bons de alguma forma. ${ }^{3}$

Uma outra série de sentimentos era associada ao livro. $\mathrm{O}$

\footnotetext{
${ }^{3} \mathrm{O}$ argumento central é de que, nesse período, a censura não era uma condição prévia da leitura, como queriam alguns líderes católicos e como seria o caso no pós-1930.
} 
desejo ou a posse efetiva de um determinado livro geravam diversas outras emoções nos leitores. A primeira - e mais facilmente evidente - era a felicidade da posse de um objeto desejado. Alberto Manguel nos fala do mais famoso ladrão de livros da história - com o significativo nome de batismo de Guglielmo Libri - e sua extensa ação sobre as obras confiscadas pela Revolução Francesa. Segundo Manguel "o prazer de segurar um volume raro nas mãos, de virar as páginas que ninguém virará sem nossa permissão, com certeza movia Libri até certo ponto" (MANGUEL, 1997, p. 273).

É em um sentido próximo que, ao explicar a gravura intitulada "um homem feliz", o escritor d'A Galeria Illustrada afirmava, em 1889:

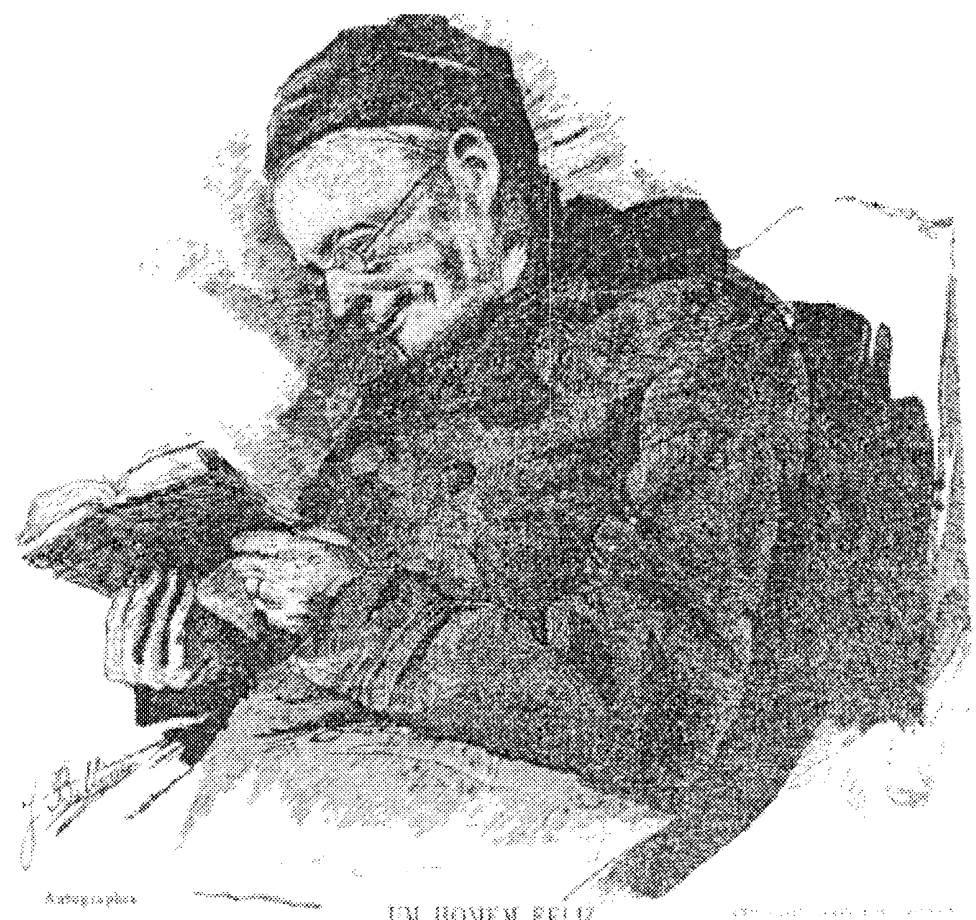


Eis o homem feliz: descobriu em um montão de papéis velhos um exemplar poeirento duma edicção ha muito tempo esgotada. [...]

Jamais amante algum ficou mais absorto pelo pensamento no seu bem amado, que o nosso velho lettrado, pelo magnifico volume, com o qual vai enriquecer a sua collecção. ${ }^{4}$

Esse desejo de posse levava à formação de bibliotecas particulares, ou à simples guarda de livros e/ou escritos em geral. Hypólito Pereira, relatando sua infância, afirmou ter desejado um livro ansiosamente (embora depois aprendesse que não era um livro tão valioso quanto esperava). Mas o mero desejo pelo livro levou-o a arquitetar um plano que enganasse o verdadeiro dono do livro, bastante cioso de seus pertences:

comecei a assedial-o para que me cedesse o livro.

Foi tudo em vão, até que tomei a resolução heroica de,pela violencia ou pela persuação,- conseguir o livro. [...] Depois de procurar interessal-o sobre umas histórias de velhos sellos, que ia, muito de industria, architectando, procurei tirar, furtivamente, o livro ambicionado, quando o velho Pampôlha, fitandome [sic.] com ironico sorrizo de quem descobrira o engôdo, disse, passando a mão sobre o hombro: -

-Deixe voce ahi o livro, porque a sua história de sellos já está muito comprida!

Escuzado será dizer que capitulei, vencido ante aquella delicada censura, com que o maniaco dos livros defendia o seu precioso thesouro. (PEREIRA, 1920, p. 9).

${ }^{4}$ Nossas gravuras - um homem feliz (cópia do Sr. Bellini). A Galeria Illustradal (17), Curitiba, 20/jul./1889p. 19-20. 
Assim como Hypólito Pereira, outros leitores (tão privilegiados quanto aquele, por serem também escritores), referiram-se, em diferentes momentos, à felicidade da posse, ou o desejo por ter em mãos e poder ler um livro desejado. Leoncio Correia comentou, em 1895, a felicidade que sentia em possuir os originais de uma obra inédita de Fernando Amaro, para cuja publicação (pelo Cenáculo) estava preparando o prefácio (CORREIA, 1895, p. 85). À mesma época (1898), o desejo de ler La Liberté, de Stuart-Mill serviu de pretexto para um convite a associar-se ao Club Coritibano e, conseqüentemente, desfrutar da rica biblioteca daquela instituição (Anon., 1898, p.1) Em um ângulo um pouco diferente, Dario Vellozo, analisando a existência de magia negra no Estado, verificava que O Livro de São Cipriano era uma fonte requisitada sobre tal assunto, que era "encontrado por baixo preço nas livrarias" e constituía "o preciozo thezouro de quanto ignorante e mentecapto se arroga a pretenção de ser Adepto" (VELLOZO, 1900, p. 65-73. /Grifos do autor/.)

Tais sentimentos despertados pelos livros podem ser melhor compreendidos à luz de uma sociedade na qual a informação - e principalmente a nova informação - era transmitida pela escrita. Era também uma sociedade na qual o novo e o inédito tinham um papel fundamental, carregado de signos de uma modernidade desejada ou existente (Ver: BERBERI, 1998; Sobre o aspecto feérico do novo e do inédito ver: DENIPOTI, 1994 e BRANDÃO, 1994). Esse sentimento de desejo pelo novo inspirava e impulsionava a imprensa periódica e, de uma forma geral justificava a própria existência de jornais, além de servir de estímulo ao surgimento de novos livros, esperados impacientemente por quem sabia que o livro sairia:

Está no prelo e brevemente será posto á venda a magnifica novella anti-clerical "Abutres!", do nosso jovem e distincto patricio Roberto Faria, um dos mais fortes talentos da nova geração literaria paranaense.

Com ancia esse livro é esperado no circulo intelectual da nossa terra (Anon., 1907). 
As relações entre leitores e livros ficam um pouco mais explícitas nesses raros momentos em que à leitura, associamse sentimentos de gama tão variada. Detectam-se relações de amor e ódio para com os livros, como aquela estabelecida por Guiomar Torrezão, na qual os livros exerciam uma irresistível e envolvente sedução sobre o leitor, a leitura tornando-se um doce sacrifício.

Outras relações entre leitores e livros podem, contudo, ser estabelecidas. Havia, por exemplo, uma forte identificação do romantismo lírico contido nos livros, em especial os de poesia, com um grupo particular de leitores: as mulheres jovens. Nesse sentido, o resenhista d'A Flammula dizia, em 1922, que Rodrigo Jr era "o poeta da moda, o artífice de pequenas joias, e rara [era] a senhorita elegante que não o [folheava] nas suas horas de leitura" (Anon. 1922, p. 21). Da mesma forma, a poesia de Francisco Leite em A hora da mulher (1920) era uma obra que se abria "á leitura e meditação, em brancas e delicadas mãos de jovens leitoras patrícias, na colheita de luminosas projecções desprendidas da alma do poeta [...]" (Anon., 1920, p. 78-79). Além da poesia, as mulheres eram vistas, por esses resenhistas, como público ideal de uma literatura leve, abundante nas livrarias paranaenses. Assim, em 1898, o conselho do escritor às leitoras que pudessem ficar chocadas com um conto de amor em que ninguém sobrevivia, era categórico:

Leitoras, si ficou gravado em vossa imaginação alguma sombra pavorosa de toda essa mortandade distrahi-vos lendo o Campo das Papoulas de Paulo de Koch.

É uma obra muito pandega, e estou certo de que si a pedires ao papá elle imediatamente vos arranjará (Anon., 1898B, p. 1).

Naturalmente, não só as mulheres eram leitoras suscetíveis a opiniões consagradoras em detrimento de experimentações artísticas. Havia um senso-comum com relação ao que constituía uma leitura fácil, descomplicada, que se opunha àquelas novas leituras que os resenhistas e colunistas buscavam. 
Esse senso pode ser verificado nas listagens de retiradas da Biblioteca Pública do Paraná, que apontam para uma ampla preferência por obras consagradas do romantismo brasileiro, como as de Joaquim Manoel de Macedo e José de Alencar, em detrimento de uma literatura mais complexa e elaborada de Machado de Assis, por exemplo.(DENIPOTI, 1994B,. p. 44). Uma verificação adicional é fornecida por uma crônica de 1898, na qual existe a crítica aberta àqueles que apregoam como única leitura viável, a de uma literatura "de facil intelligencia e portanto (Illação perfeitamente logica) aproveitam muito, ao passo que os outros livros não valem a capa":

Ora estava eu um dia a saborear a prosa scintilante e fina das Farpas, de Ortigão, o grande escriptor portuguez.

Surprehendeu-me n'essa agradavel leitura um d'esses sujeitinhos de que falei acima.

O meu amigo bate-me ao hombro e me pergunta: "Então, que estas lendo? ... As Farpas? ... não te gabo o gosto; essa história nem tem sentido... Queres ler coisa soberba? Pois pega na Princesa Magalona, ou no Carlos Magno, mas isso... oh! é perder tempo..."

Eu lancei-Ihe um olhar, myxto de penna e ironia, e Ihe disse, qual si confirmasse o que elle dissera: "Tens razão, amigo, é perder tempo lêr um livro como esse... Leitura excellente tem a gente na História da Avósinha..."

E d'ahi a pouco, quando o vi pelas costas, pude respirar e fui admirar as proezas do engenhoso Bertholdo empavezado (Anon. 1898C, p. 2).

Esse tipo de leitor, comumente menosprezado na imprensa, mais facilmente - mas não exclusivamente - associado à leitura feminina, existiu e conviveu com leitores mais exigentes, como a maioria dos jornalistas e escritores paranaenses que forneceram as fontes para este estudo. Estes últimos, dos quais 
os exemplos citados até o momento podem dar uma idéia, ainda que incompleta, eram responsáveis por tentativas de superar a leitura "fácil" estabelecendo, ou tentando estabelecer, novos cânones de leitura para uma parcela maior da sociedade. Essas tentativas acabavam por ir de encontro a freqüentes identificações da leitura com conceitos de verdade.

As formas como os diversos leitores leram, embora sejam recuperadas fragmentariamente, quanto a uns poucos livros para cada leitor, (às vezes, um único livro por leitor, ou um único leitor por livro) são um caminho de acesso à compreensão da leitura no passado que está em foco aqui. Em mais uma longa lista de exemplos, o primeiro é a leitura que Emiliano Pernetta fez de Aristófanes, que remeteu o leitor à história relatada, fazendo-o ouvir "ainda a chalaça brutal das plateias de Athenas, o rugido sangrento da plebe iconoclasta e irreverente, que assassinou de improperios, de chufas e de infamias, Socrates, o filosofo" (PERNETTA, 1913, p. 319-323). Outro leitor a descrever suas impressões foi Rocha Pombo, em sua leitura do romance $A$ Carne. Pombo descreveu seu percurso de leitura com bastante precisão, demonstrando as emoções mistas que a obra the despertou:

Quando li as primeiras páginas do livro de Julio Ribeiro, senti-me arrebatado de enthusiasmo pelo grande talento do autor. De período a período eu intercalava umas interjeições que bem significavam a minha alegria por ter uma prova tão brilhante de que meu paiz já não tinha que invejar ao velho Portugal, com toda a sua opulenta geração de grandes homens. A algum amigo cheguei mesmo a dizer que já estava orgulhoso de poder oppor um igual a Eça de Queiroz. Continuei a leitura, com um interesse que eu mesmo estranhava. Do capítulo XIII em diante comecei a suspeitar que o talento do autor tivesse de cahir adiante, pois ele subira muito. O capítulo immediato feriu-me. Mas de pé, ainda, alevantado, o romancista se me apresentava cada vez mais admirável através daquellas páginas scintillantes, de immaculada correção e de elegancia infinita. 
Julio Ribeiro porém, deu-me bem cara essa admiração, esse prazer, esse orgulho que me fez sentir. Fez-me pagar tudo com uma decepção tremenda. Vingou-se com uma crueldade incrível, com uma espécie de brutalidade genial que arrepiou-me até a raiva... (ROCHA POMBO. 1888, p. 28).

As leituras são registradas em termos de emoções que despertam no leitor, e que ele, buscando expandir seus sentimentos, por sua vez, aos seus próprios leitores, coloca em letra impressa nos periódicos. Lendo a poesia do paulista Carvalho Aranha, em 1898, o resenhista utiliza-se dessa tentativa de transferência de sensações:

Ao lêr esse bello ramilhete, sente-se a espontaneidade da sua concepção e affigura-se-nos vêl-os a brotar esponte da penna do jovem poeta, como um veio de agua chrystalina, eclodindo da terra... (Anon., 1898D, p. 1).

As expressões de leitura que recolhemos e elencamos demonstram uma admiração incontida pela palavra impressa, seja poema ou prosa, literatura ou ciência. Que as manifestações dessa admiração se dêem em elogios do estilo, ou em alegorias construídas em torno do ato de ler, serve como reforço para a visão que buscamos mostrar de uma sociedade orientada por e para a leitura e a palavra impressa.

Para finalizarmos, apresentaremos duas leitoras que, em um espaço de nove anos, apresentam suas leituras de Eurico, $o$ presbítero, de Alexandre Herculano. Ambas as leituras foram publicadas em periódicos do Instituto Neo Pitagórico (INP), o que sugere uma leitura "iniciática", ou feita com o intuito de aprender ou iniciar-se nos mistérios do neo-pitagorismo, parte do "fio de Ariadne no labyrintho dos livros" que Dario Vellozo acreditava levarem à "Crótona" e ao conhecimento (VELLOZO, 1913).

"Djenane", a primeira leitora, embebeu-se na leitura a ponto de perder a noção do tempo, as horas correndo velozes "quando meo espirito se embevece na meditação dos seos trechos". Concordando com o autor do romance, a leitora recuperou da 
obra as passagens que mais the agradaram, ou com as quais concordava. Assim ela pensava "com Herculano que a palavra sacerdote [queria] dizer 'so e triste"', e concordava com ele em várias passagens que descreviam o estado emocional do personagem, a quem não era dado o lenitivo da lágrima "pois as tempestades do passado estancaram-nas ao brotarem". Continuando, a leitora expressava sua admiração:

É sublime quando Herculano descreve as noites em que o seo personagem, vagando so, pelos altos rochedos escarpados, pensando e em palestra, sem vontade propria, com a sua Hermengarda, perdida para sempre, recorda os tempos em que era feliz, porque tinha esperança, e, voltando ao romper da aurora ao presbyterio, inspirado o seu genio de poeta, entregavase á construcção de estrophes repassadas de amor e saudade, e que eram dirigidas á noiva morta. E o clero adoptava-as, repetia-as; porem ignorava a causa da inspiração do poeta e interpretava-as a seo bel prazer.

Envolta nesses sentimentos, descreve em maiores detalhes sua forma de ler, na qual sente "verdadeira satisfação cada vez que, a sos, posso dedicar-lhe alguns momentos estudando-lhe o estylo sadio e o modo de encarar o sacerdócio" (DJENANE, 1918, p. 112-14).

"Lisette", a segunda leitora, demonstrou sensações bastante semelhantes, pois exclamou, logo de início; "Que de momentos ditosos me proporcionou o solitario de Val-de-Lobos [Herculano]!" A leitora declarava-se envolta em serenidade e empolgada pelo bem supremo da obra. Sua leitura foi afoita, pois "avido, meo olhar se embrenhou nas páginas buriladas: oh Mestre! na preocupação superna de descortinar-se o bello, o verdadeiro". Sua opinião sobre o autor era extremamente lisongeira:

Herculano não escreve com palavras, mas com a alma das palavras. O Eurico é como o pharol que allumia a senda, ao fragil esquife do garimpeiro do saber, no mar bonançoso ou encapellado, que é a vida. 
Para ela, o livro assumia características místicas, pois havia "nas páginas do Eurico o fresco alvor das rosas de maio, o alvinitente do marmore que o resguarda, no grandioso mausoleo dos Jeronymos" (LISSETE, 1927, p. 20-21).

Ambas as leituras demonstram uma reação empolgada à obra do escritor lusitano, que parece não ser unicamente justificada por suas características literárias, mas por uma verdadeira adoração à obra e ao autor. Pensarmos que suas leituras foram descomprometidas é ignorarmos o fato de que as autoras pertenciam e freqüentavam um instituto dedicado à leitura e ao debate em torno de uma proposta de união entre as tradições intelectuais do Ocidente e do Oriente. O fato de suas impressões de leitura terem sido publicadas é também significativo, considerando a forte influência de Dario Vellozo nas atividades do INP, particularmente nas publicações, sendo ele seu fundador e principal líder. Tratam-se, portanto, de leituras autorizadas e sacralizadas dentro da instituição, com o provável aval de seu mentor, cuja influência sobre os membros do instituto fica patente nos vários periódicos, empreendimentos e ações do INP.

O quadro geral das leituras no Paraná do meio século entre 1880 e 1930 tem características gerais que podem ser, de uma certa forma, resumidas nas duas leituras emocionadas descritas acima. Por um lado, há uma forte predisposição dos leitores para se envolverem emocionalmente com os textos, conforme as diversas imagens arroladas neste capítulo procuram demonstrar. Por outro, há uma tentativa, partindo de diversas fontes, de que as leituras sejam disseminadas pela sociedade, através da publicação de resenhas ou impressões, nos diversos periódicos que circularam no período. Há também, em escala menor,

\footnotetext{
${ }^{5}$ A verdadeira revolução da leitura localiza-se, segundo CHARTIER, a partir do século IX, nos mosteiros, e a partir do século XIII, nas universidades européias e a partir daí para a sociedade leiga. Em essência, a leitura silenciosa é a grande mudança no modo de ler que Chartier identifica como revolucionária: "A leitura silenciosa de fato estabelece um relacionamento mais livre, mais secreto e totalmente privado com a palavra escrita. Permite uma leitura mais rápida, que não é impelida pelas complexidades da organização do livro e as relações estabelecidas entre o discurso e as glosas, as citações e os comentários, o texto e o índice. Também permite usos diferenciados do mesmo livro: dado o contexto ritual ou social, ele pode ser lido alto para ou com outras pessoas, ou pode ser lido silenciosamente para si mesmo no abrigo do estúdio, da biblioteca ou do oratório". CHARTIER, 1988. p. 18-19.
} 
tentativas de direcionar ou conduzir tais leituras conforme planos definidos, freqüentemente dogmáticos (ainda que quase nunca estabelecendo uma ortodoxia que dominasse todo o quadro de leitores). Esses planos podiam estar comprometidos com conjuntos de idéias (católicas, liberais, iluministas, neopitagóricas), ou com ideais estéticos (simbolismo, modernismo). O fato de que nenhum padrão extremamente rígido controlasse a forma como esses indivíduos eventualmente leram, aponta para uma leitura plural, voltada para a busca da novidade ou do inédito com a mesma dedicação que estava voltada para clássicos da tradição ocidental. Uma leitura livre, feita preferencialmente a sós, ${ }^{5}$ mas que não excluía a leitura pública, em grupos razoavelmente homogêneos, como os membros do INP, ou visitas em uma noite qualquer de verão.

Assim, com a abundância de material de leitura que permitia uma constante atualização, os paranaenses podiam exercer uma leitura extensiva, no conceito elaborado simultaneamente por Engelsing e Hall, (DARNTON, 1989, p.199236; HALL, 1989) alimentando suas próprias ambições literárias, intelectuais e científicas através de um mercado editorial dinâmico, que aumentava a quantidade (não falamos aqui da qualidade dos trabalhos) de palavra impressa à disposição, em um moto-contínuo que caracteriza a transmissão de idéias e de cultura, no sentido antropológico do termo, da sociedade ocidental.

Abstract: This article presents some of the results of the research on reading in the past, done from sources in Paraná of the turn of the century. The article tries to understand how reading itself was understood and represented in the past, starting from local cases. Key-words: History of reading - History of Brazil - Reading

\section{Referências Bibliográficas}

Anon. 1896. Respigas. Cenáculo I/(3). Coritiba, 1896, p. 157160

Anon. 1897. Respigas. Cenáculo III (4). Curitiba, 1897, p. $187-$ 190. 
Anon. 1898. Ser e não parecer. O Sapo I (14) Curitiba, 05/jun./ 1898, p. 1.

Anon. 1898B. "Ralé-Rey". Defendendo-me. O Sapo I (21), Curitiba, 24/jul./1898B, p. 1.

Anon. 1898C. Juizes... sem juizo. O Sapo / (19) Curitiba, 10/jul./ $1898 \mathrm{C}$, p. 2.

Anon. 1898D. Primicias. O Sapo I (19) Curitiba, 10/jul./1898D, p. 1.

Anon. 1907. O Olho da Rua (3). Curitiba, 02/maio/1907 s./p.

Anon. 1920. Bibliographia. O Itiberê I/(12). Paranaguá, abr./1920, p. 78-79.

Anon. 1922. O que vem de apparecer. A Flammula I (2), Curitiba, jun./1922, p. 21.

BERBERI, Elizabete. 1998. Impressões; a modernidade através das crônicas no início do século em Curitiba. Curitiba: Aos Quatro Ventos, 1998.

BRANDÃO, Angela.1994. A fábrica de ilusão; o espetáculo das máquinas num parque de diversões e a modernização de Curitiba. 1905-1913. Curitiba: Fundação Cultural de Curitiba, 1994.

CHARTIER, Roger. 1988. Frenchness in the History of the book, from the history of publishing to the history of reading. Worchester: American Antiquarian Society, 1988.

CORREIA, Leoncio. 1895. Galeria Paranaense. Cenáculo I (1), Coritiba, 1895, p.85; 253.

DARNTON, Robert. 1989. História da Leitura. In: BURKE, Peter. A escrita da história; novas perspectivas. São Paulo: Ed. Unesp, 1989, p.199-236.

DENIPOTI, Cláudio. 1994. Fashionable images; the world of fashion through photographic images of the turn-of-thecentury - a case study. Iberoamericana - Nordic Journal of Latin American Studies XXIV (2) Stockholm, 1994, p.2-18.

1994B. Páginas de prazer, a sexualidade através da leitura no início do século. Curitiba, 1994B, Dissertação Mestrado, Universidade Federal do Paraná.

1998. A sedução da leitura; livros, leituras e história cultural. Paraná - 1880-1930. Curitiba, Tese, doutoramento, UFPR, 1998. 
1998B. Deusdedit, Joakim, seus livros e autores.: Revista Brasileira de História 35(18) p. 307-328, São Paulo: ANPUH/ Humanitas, 1998B.

DJENANE, 1918. Impressões (em torno do Eurico). Myrto e Acacia III (11 e 12), Curitiba, primavera e estio, 1918, p. 11214.

GAY, Peter. 1990. A experiência burguesa da rainha Vitória a Freud; a paixão terna. São Paulo: Companhia das Letras, 1990.

HALL, David. 1989. Worlds of wonder, days of judgement, popular religious belief in early New England. New York: Knopf, 1989. LISSETE. 1927. Impressões da leitura de Eurico. Luz de Krotona $V(1)$. Curitiba, mar./1927, p.20-21.

MANGUEL, Alberto. 1997. Uma história da leitura. São Paulo: Companhia das Letras, 1997.

MOSCOVICI, Serge. 1990. Psycologie sociale. Paris: PUF, 1990. MOURA BRASIL, Deusdedit. 1920. Ontogenia do direito commercial; dissertação e theses de concurso para prehenchimento do cargo de lente substituto [...] da faculdade de direito do Paraná. Coritiba: Empreza Graphica Paranaense, 1920.

PEREIRA, Hypolito. 1920. Os typos inconfundiveis - O Pampolha. O Itiberê // (9), Paranaguá, jan./1920, p. 9.

PERNETTA, Emiliano. 1913. A proposito do Centro de Letras do Paraná. Fanal III $(15,16,17)$, Curitiba, Abr, maio, jun./1913, p. 319-323.

ROCHA POMBO. 1888. A carne (romance de Julio Ribeiro). A Galeria Illustrada I, (4). Coritiba, 20/dez./1888, p. 28.

TORREZÃO, Guiomar. 1889. Letras e artes - Livros novos. $A$ Galeria Illustrada I (10) 10/abr./1889, p. 82.

VELLOZO, Dario. 1900. Ocultismo no Paraná. Esphynge II(1), nov./1900, p. 65-73.

VELLOZO, Dario 1913. (Appolonio de Tyana). Luz de Krotona. Curitiba, s./ed., Janeiro de 1913. s./p.

1916. (Appolonio de Tyana). Da irradiação pithagorica em Paulo e Virginea de B. de Saint-Pierre. Myrtho e Acacia I (2), Curitiba, mar.-maio/1916, p. 112-145. 